\title{
An Evaluation on the Effects of the Policy of the Great Campaign of Western Development of China in the First 10 Years-Based on the Kuznets Regional Inverted-U Theory*
}

\author{
Huan Zheng, Xingming Fang \\ Southwestern University of Finance and Economics, Chengdou, China
}

\begin{abstract}
In order to reduce the regional differentials or narrow the gap in economic development between eastern and western areas and prevent the intensification of contradictions resulting from the regional inequality during the development process, the government of China launched the Great Campaign of Western Development (GCWD) in 2000. In this paper, we will evaluate the effects of the first 10 years' GCWD and use the latest Chinese annual data from 1978 to 2010 to investigate the problem of regional differentials in the development process, evaluate the effects of GCWD policy and test whether there is a regional Kuznets inverted-U curve in the regional development of China. The result shows that there are both good and bad news: the good news is that the inverted U-shaped curve of absolute differential between eastern and western areas finally emerges (the previous studies showed that the inverted-U curve did not appear and the differentials between eastern and western areas became worse) and the bad news is that the differential is in the first half of the inverted U-shaped curve in our choice of time span (1978-2010), that is, it is still in the situation of deterioration, and the turning better point will emerge in 2025. Although the western areas have benefitted from GCWD, the absolute gap has been still widened. To narrow the gap, the western areas should accelerate the industrial development and the government should adjust the policy and make more efforts to support the development of the industry in the western areas, especially cultivate and support the development of the western characteristic and advantageous industry rather than just supporting the construction of infrastructure in the western areas.
\end{abstract}

Keywords: Great Campaign of Western Development (GCWD), the gap between eastern and western areas, regional inequality or differential, inverted-U curve

\section{Introduction}

China has gained great economic development since reform and opening 30 years ago but meanwhile there has been a serious regional inequality in the development process. Because of the location advantages, the eastern coastal areas have attracted more domestic and foreign investment so as to gain much faster development and the western inland areas have been in a backward. Furthermore, the gap between eastern and

\footnotetext{
* This paper is funded by Fourth Project of Construction of "211 Project" of Southwestern University of Finance and Economics. Huan Zheng, Ph.D. candidate in Economics School, Southwestern University of Finance and Economics.

Xingming Fang, Ph.D., Professor, Research Fellow, Director of the Institute of National Economics, Economics School, Southwestern University of Finance and Economics.

Correspondence concerning this article should be addressed to Huan Zheng, The School of Economics in Southwestern University of Finance and Economics, Wenjiang District, Chengdou City, China. E-mail: zheng19871109@126.com.
} 
western areas has been increasingly widened. In order to narrow the gap and prevent the intensification of contradictions resulting from the regional inequality, the government of China launched the Great Campaign of Western Development (GCWD) in 2000. The aim of the first 10 years' GCWD was to support the construction of infrastructure in the western areas to accelerate the economic development of the western areas. During the 10 years from 2001 to 2010, the infrastructure in western areas was improved unprecedentedly and the economic growth rates were higher and higher, then from the beginning of 2006 the growth rates in the western areas were even higher than that in the eastern areas. Thus, in this paper we will evaluate the degree of the achievement of government objectives, verify whether the absolute gap between the eastern and western areas was narrowed and test whether there is a Kuznets regional inverted-U curve in the economic development between the two regions.

\section{Related Literature Review}

In regional economics there is a famous theory-regional Kuznets inverted-U hypothesis which was put forward by American economist Jeffrey G. Williamson in 1965, he used the data of 24 countries from 1949 to 1961 to investigate the relationship between regional dualism and national economic development and his conclusion was that there has been a consistent relationship between the two: rising regional income disparities and increasing north-south dualism is typical of early development stages, while regional convergence and a disappearance of severe north-south problems is typical of the more mature stages of national growth and development (Williamson, 1965). That is to say, economic development brings an initial phase of deterioration in regional inequality (or rising regional income disparities) followed by subsequent phase of improvement. This is the main idea of famous regional Kuznets inverted-U theory.

With regard to regional inequality or regional differentials between eastern and western areas in China, there has been a considerable amount of researches. Through analysis of the Lorenz curve of per capita Gross National Product (GNP) in 1978-1992, Yang (1992) concluded that the regional differentials of China has been declining significantly, not increasing since reform and opening of China. Later, almost all the scholars drew a conclusion that the regional inequality or differentials between eastern and middle-western areas have been higher and higher and the gap of middle-western areas become larger compared with the eastern areas, therefore there has been no regional Kuznets inverted-U type curve in the economic development process of China (Liu, Li, \& Xue, 1985). Zhou and Lu (2005) concluded that the economic differentials among Chinese coastal provinces have been declining and the differentials between China's coastal and inland provinces been increasing since the 1990s.

In addition, many scholars analyzed the reasons of the gap between eastern and western areas. Cai and Du (2001) held that the reasons for the gap are the differences in the level of per capita income, urbanization, industrialization, human resource endowment between the eastern and western areas. Guo and Wang (2003) attributed the reason for the regional differentials of China after 1990s to the difference in capital flow between the eastern and western areas. Wang and Fan (2004) held that productivity, urbanization level, commercialization of scientific and technological achievements were also the reasons for the differentials in addition to capital flow. Yang (2005) analyzed the data from 1997 to 2002 and attributed the differentials to the difference of regional industrial structure.

Seen from above-mentioned literatures, the scholars have discussed the problem of regional inequality and the gap between the eastern and western areas of China from different angles, and most of them did not support 
a regional inverted-U curve in the economic development process in China. Since China has launched GCWD in 2000, it is necessary to analyze the impacts of GCWD policy on the economic development of western areas and further to check whether a regional inverted-U curve emerges in the differentials between eastern and western areas ${ }^{1}$. The data we select are from China Statistical Yearbook (2011) and the time period is 1978-2010 which include the period of 2001-2010, just 10 years for GCWD policy implemented.

In the selection of indicators which reflect economic growth, we use the per capita GDP instead of per capita income because the National Statistics Bureau does not release the indicator of per capita income and the per capita GDP is better than total GDP in reflecting true level of economic growth (the data are shown in Appendix Tables A1 and A2). In order to truly reflect the variation of per capita GDP, we have adjusted data of nominal per capita GDP with price index (taking 1978 price for deflating). In data processing, we conduct a stationary test and cointegration test to rule out the existence of the spurious regression among variables. In the methodology, we have tried to use the method of panel data, but the model cannot pass the test, so we use time series model which is also generally accepted by scholars. In addition, we have also made qualitative analysis to search for the reasons for the regional differentials between eastern and western areas in the economic development process of China.

\section{Empirical Study}

We will study two aspects below: the absolute regional differential and growth rate differential between eastern and western areas.

Now we set up a cubic equation model to analyze the type of the differential relationship between eastern and western areas in China:

$$
\ln S_{t}=\beta_{0}+\beta_{1} \ln y_{t}+\beta_{2} \ln ^{2} y_{t}+\beta_{3} \ln ^{3} y_{t}+\varepsilon_{t}
$$

where $S$ is the standard deviation which is used to measure the absolute differential, $S=\sqrt{\frac{\sum_{i}^{N}\left(y_{i}-\bar{y}\right)^{2}}{N}}, y_{i}$ is the real per capita GDP of region $i, \bar{y}$ is the mean value of real per capita GDP of the regions, $N$ is the numbers of regions, $y_{t}$ is the value of real per capita GDP of the western region, $\varepsilon_{t}$ is the random error term. ${ }^{2}$

\section{A Stationary Test on Variables}

Now that the time series model is used, it is necessary to conduct a stationary test on the data. If the data is stationary, we can go on with regression analysis, or else we should conduct cointegration test on the model to rule out the existence of spurious regression. This paper adopts augmented ADF test to verify the stationarity of the tested variables and after $\mathrm{ADF}$ test of the data, we find that $\ln S$ and $\ln y$ are first-order integration sequences (the results are shown in Table 1). All the two variables are non-stationary. So we can do modeling analysis, but we have to conduct the cointegration test on the variable sequences first to avoid spurious regression.

\footnotetext{
1 The eastern areas consist of 10 provinces or municipalities: Beijing, Tianjin, Hebei, Liaoning, Shanghai, Jiangsu, Zhejiang, Fujian, Shandong, Guangdong and the western areas consist of 12 provinces, autonomous regions, or municipalities: Chongqing, Sichuan, Guizhou, Yunnan, Tibet, Shanxi, Gansu, Qinghai, Ningxia, Xinjiang, Inner Mongolia, and Guangxi.

${ }^{2}$ There can be following possible curves: If $\beta_{1}>0, \beta_{2}<0, \beta_{3}>0$, the curve is cubic or $N$-type, on the contrary, if $\beta_{1}<0, \beta_{2}>0$, $\beta_{3}<0$ the curve is inverted $N$-type; If $\beta_{1}>0, \beta_{2}<0, \beta_{3}=0$, the curve is quadratic or Kuznets inverted U-type, on the contrary, if $\beta_{1}<0, \beta_{2}>0, \beta_{3}=0$, it is U-type; If $\beta_{1}>0, \beta_{2}=0, \beta_{3}=0$, it is linear.
} 
Table 1

The Results of ADF Test

\begin{tabular}{llllll}
\hline Variable & ADF test statistic & $1 \%$ critical value & $5 \%$ critical value & $10 \%$ critical value & Result \\
\hline $\ln S$ & $(0,0,0)$ & 9.400806 & -2.639210 & -1.951687 & Non-stationary \\
$\ln y$ & $(0,0,6)$ & 5.188679 & -2.656915 & -1.954414 & Non-stationary \\
$\Delta \ln S$ & $(\mathrm{C}, 0,0)$ & -4.170109 & -3.661661 & -2.960411 & stationary \\
$\Delta \ln y$ & $(\mathrm{C}, 0,0)$ & -3.767806 & -3.661661 & -2.960411 & Stationary \\
\hline
\end{tabular}

\section{A Cointegration Test}

Now we use the method of the Johansen cointegration test (Johasen, 1991) to test the cointegrating relationship (the results are shown in Table 2). ${ }^{3}$ According to the results in Table 2, we can conclude that there is a long-run equilibrium relationship between $\ln S$ and $\ln y$.

Table 2

The Results of Johansen Cointegration Test

\begin{tabular}{lccccc}
\hline Null hypothesis & $\lambda$ & Trace $(P$ value $)$ & $\begin{array}{l}5 \% \text { critical value } \\
\text { (trace statistics })\end{array}$ & $\lambda_{\max }(P$ value $)$ & $\begin{array}{c}5 \% \text { critical value } \\
\left(\lambda_{\max }\right.\end{array}$ \\
\hline Statistics $)$
\end{tabular}

\section{The Empirical Analysis}

Wald Test. The Wald Test is a parametric statistical test named after Abraham Wald with a great variety of uses. It can be used to test the true value of the parameter based on the sample estimate. In this paper, we consider the following model:

$$
\ln S_{t}=\beta_{0}+\beta_{1} \ln y_{t}+\beta_{2} \ln ^{2} y_{t}+\beta_{3} \ln ^{3} y_{t}+\varepsilon_{t}
$$

The Wald Test can be used to test whether the coefficient of $\ln ^{3} y$ is equal to zero. Write this as $\mathrm{H}_{0}: \beta_{3}$ $=0$ versus $\mathrm{H}_{1}: \beta_{3} \neq 0$ Table 3 reports the result of the Wald Test.

Table 3

The Results of Wald Test

\begin{tabular}{lllll}
\hline Null hypothesis & Test statistic & Value & $d f$ & Probability \\
\hline \multirow{2}{*}{$\beta_{3}=0$} & $F$-statistic & 0.039622 & $(1,29)$ & 0.8436 \\
& Chi-square & 0.039622 & 1 & 0.8422 \\
\hline
\end{tabular}

Since there are 29 degrees of freedom, the $F$-statistic for $\hat{\beta}_{3}$ is $0.039622, p$-value is about 0.8436 , so we reject the alternative in favor of the null at even very large significant levels. We also say that " $\hat{\beta}_{3}$ is statistically equal to zero at the appropriate significance level”. Hence, we obtain a more suitable equation:

$$
\ln S_{t}=\beta_{0}+\beta_{1} \ln y_{t}+\beta_{2} \ln ^{2} y_{t}+\varepsilon_{t}
$$

Testing for serial correlation. We estimate equation (2) by OLS:

$$
\begin{array}{r}
\ln S_{t}=-7.114904+2.932043 \ln y_{t}-0.147242 \ln ^{2} y_{t}+\varepsilon_{t} \\
\mathrm{se}=(0.846845)(0.247196)(0.017840)
\end{array}
$$

\footnotetext{
3 There are two methods for cointegration test: Engle-Granger (EG) two-step approach and Johansen cointegration test, the cointegration test pioneered by Engel and Granger (1987), but the EG method cannot deal with the case where more than one cointegration relationship. Since the two variables are integrated of order two, we use the Johansen test.
} 


$$
\begin{gathered}
t=(-8.401657)(11.86123)(-8.253518) \\
R^{2}=0.993496, D W=0.596241, F=2291.245(0.0000)
\end{gathered}
$$

When there is a serial correlation in the error terms of a multiple regression model, OLS is no longer BLUE in the presence of serial correlation. Even more important, the usual OLS standard errors and test statistics are not valid. So we must test for the presence of serial correlation in the multiple regression model. In this study, we use the DW test for serial correlation in model (3) and then obtain the DW computed to be DW = 0.596241 . We can get the $5 \%$ critical value from the statistical table about critical values of the DW distribution for $k=2, n=33$, the DW with two sets of critical values are: $d_{U}=1.577, d_{L}=1.321$. According to the DW test criterion, $0<\mathrm{DW}<d_{L}(0.596241<1.321)$, we reject the null of no serial correlation at the $5 \%$ level, That is to say this model has a positive serial correlation.

Correcting for serial correlation. Now we use the generalized difference method to confirm the order of the autocorrelation:

$$
\begin{aligned}
& \hat{\ln S_{t}^{*}}=-2.313212+2.998179 \ln y_{t}^{*}-0.151608\left(\ln y_{t}^{2}\right)^{*} \\
& \mathrm{se}=(0.633323)(0.570229)(0.039926) \\
& t=(-3.652502)(5.257849)(-3.797208) \\
& R^{2}=0.963462, D W=1.950356, F=382.3490(0.0000)
\end{aligned}
$$

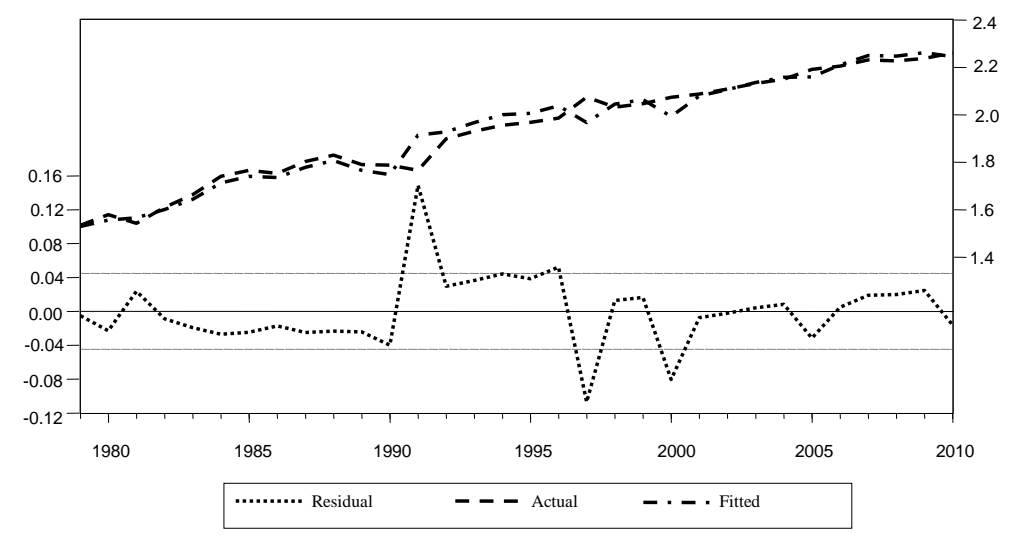

Figure 1. The trend chart of absolute differential between estern and western area.

Because we use generalized differential data, the sample size reduces 1, equates to 32 . We obtain the DW compute to be DW $=1.950356$. We get the $5 \%$ critical value from the statistical table about critical values of the DW distribution for $k=2, n=32$, we can get the $5 \%$ critical value from the statistical table about critical values of the DW distribution for $k=2, n=33$, the DW with two sets of critical values are: $d_{L}=1.309, d_{U}$ $=1.574$. According to the DW test criterion, $d_{U} \leq D W \leq 4-d_{U}(1.574<1.950356<2.426)$, there is no serial correlation at the $5 \%$ level. The coefficient of determination $R^{2}, t, F$ statistical also achieves the desired level.

Analysis of the regression result. To sum up, the trend of absolute differential between eastern and western areas of China presents an inverted U-type, that is, the absolute differential between the eastern and western areas presents a process from deterioration to improvement - this is a good news which means that the expected regional Kuznets inverted-U curve in China finally emerges. The curve is ideal, but unfortunately the curve is in the first half of the inverted U curve in our choice of time span (1978-2010) seen from the chart, that 
is, the curve is in deterioration stage, so the trend of absolute differential between eastern and western areas of China is still widening. Now we denote $\xi$ as the turning point of the inverted U-shaped Kuznets Curve, $\xi$ is always achieved at the coefficient on $\ln y$ over twice the absolute value of the coefficient on $\ln ^{2} y$ :

$$
\xi=\exp \left(-\beta_{1} / 2 \beta_{2}\right)=\exp (-2.998179 / 2-0.151608)=\exp (9.887931)=19691.28
$$

Equation (5) declares that the theoretical turning point of an inverted U-shaped Kuznets curve is labeled at 19,691.28 yuan (real per capita GDP of western areas), the absolute differential between eastern and western areas of China becomes maximum between 2025 and 2006, i.e., the turning point is between 2025 and $2026^{4}$. That is to say, before 2025-2026, the absolute differential between eastern and western areas of China will be still worse but after 2026, the absolute differential will be in a narrowing trend.

\section{Comparison and Analysis}

\section{The Comparison of Growth Rates Between Eastern and Western Areas}

During the first year of GCWD, the growth rates in the western areas were still lower than that in the eastern areas, but the growth rates in the western areas have begun to be higher than that in the eastern areas since 2006, so an inverted U curve has emerged. The main reasons are analyzed as follows.

Firstly, the effects of GCWD policy have been gradually emerging. Though the effects of the GCWD policy in the first years were not obvious, in later years the effects became more and more apparent. The government-oriented investment has greatly improved the infrastructure in the western areas and meanwhile promoted economic growth in the western areas. Table 4 shows the infrastructure investment on west, east, and whole country:

- In absolute terms, the infrastructure investment in the western areas showed an upward trend year after year, from 298.38 billion yuan in 2000 to $6,189.23$ billion yuan in 2010;

- In terms of growth rate, the investment growth rate in the western regions is faster than the eastern regions. The infrastructure investment in the western areas grew at an annual average rate of $35.42 \%$ from 2000 to 2010 , about three percentage points higher than that in the eastern areas.

Secondly, Chinese economy entered a "high growth" phase as a whole from 2002 to 2007 with double-digit growth rates. During this period the high economic growth was driven by fast growing of the heavy and chemical industry which is characterized by high energy consumption. The western areas are full of energy resource and those provinces with energy advantage accelerated the development of energy-intensive industry so as to have higher growth rates than eastern areas.

Thirdly, the US financial crisis broke out in 2008 shocked the world economy fiercely and simultaneously exerted a negative impact on Chinese economy, especially the export-oriented economy in the eastern coastal areas. Due to the lower economic extroversion in the western areas of China, the economy of the western areas is not dependent on exports so that the impact of financial crisis on the western areas was much less severe than on the eastern areas. Thus, the western areas continued to maintain the higher growth rates than the eastern areas.

\footnotetext{
${ }^{4}$ To calculate the year of turning point, we base on: (1) historical change, real per capita GDP growth rate of western areas is $10.4 \%$ from 2000 to 2010 (taking 1978 price for deflating), if we use $10.4 \%$ as the real per capita GDP growth rate of western areas, calculate to 2025, the real per capita GDP of western areas will be 18,277.63 yuan. According to the historical change, the theoretical turning point of the absolute differential between eastern and western areas of China is labeled at 2025; (2) the forecast from Urban and Environmental Research Institute, Chinese Academy of Social Sciences (Western Region Development during the Twelfth Five-Year Plan and the Long-Term Development Idea Research in 2020), the real per capita GDP growth rate of western areas will be $10 \%$ during Twelfth Five-Year, calculate to 2025, the real per capita GDP of western areas will be $18,112.15$ yuan. So the turning point is between 2025 and 2026.
} 
Table 4

The Infrastructure Investment on West, East, and Whole Country

\begin{tabular}{lccc}
\hline Year & The infrastructure investment & in The & infrastructure The infrastructure investment in west \\
& whole country (billions) & investment in east (billions) & (billions) \\
\hline 2000 & $1,342.73$ & 630.91 & 298.38 \\
2001 & $1,482.01$ & 671.59 & 342.51 \\
2002 & $1,766.66$ & 787.86 & 423.57 \\
2003 & $5,556.67$ & $1,114.58$ & 560.47 \\
2004 & $7,047.74$ & $4,009.46$ & $1,375.45$ \\
2005 & $8,877.36$ & $4,945.95$ & $1,764.56$ \\
2006 & $10,999.82$ & $5,990.27$ & $2,199.69$ \\
2007 & $13,732.39$ & $7,180.89$ & $2,825.08$ \\
2008 & $17,282.84$ & $8,704.92$ & $3,594.88$ \\
2009 & $22,459.88$ & $10,685.22$ & $4,968.64$ \\
2010 & $27,812.19$ & $13,058.0$ & $6,189.23$ \\
\hline
\end{tabular}

Note. Source: China Statistical Yearbook 2001-2011.

\section{The Analysis of the Problem of Absolute Regional Differential Between Eastern and Western Areas}

The GDP of the western areas grew up from 1,707.07 billion yuan in 2000 to 5,579.93 billion yuan in 2010, increased by $226.87 \%$ (calculated by constant 2,000 RMB prices, similarly hereinafter), meanwhile, the proportion of aggregate GDP of the western areas accounting for the whole nation was showing significant increase on the whole year after year, from $17.21 \%$ in 2000 to $20.77 \%$ in 2010 - the historical highest point, increased by 3.56 percentage points. The national GDP grew up from 9,921.46 billion yuan in 2000 to $26,869.97$ billion yuan in 2010 , increased by $170.83 \%$, about 56 percentage points lower than the western areas. Comparatively the GDP of the eastern areas grew up from 5,688.51 billion yuan in 2000 to $18,076.9$ billion yuan in 2010 , increased by $217.77 \%$, about 10 percentage points lower than the western areas, the proportion of aggregate GDP of the eastern areas accounting for the whole nation was showing significant increase on the whole, from $57.34 \%$ in 2000 to $69.62 \%$ in 2010 , increased by 12.28 percentage points, with 8.72 percentage points higher than western areas. So the relative differential ${ }^{5}$ between eastern and western areas increased significantly. Furthermore, the absolute differential between eastern and western areas increased from 3,981.44 billion yuan in 2000 to 13,126.97 billion yuan in 2010, increased by $229.7 \%$ (see Table 5). Although the growth rates in the western areas were higher than that in the eastern areas since 2006, the absolute differential between them increased significantly because of the base of economic data in the western areas was far lower than that in the eastern areas. Therefore, in order to stop the trend of the increasing absolute differentials between the eastern and western areas, the economic growth rates in the western areas must be much higher than that in the eastern areas. According to the data in 2010, we can calculate that in order to stop the absolute differential to get bigger, the growth rates of the western area in 2011 should be equal to 3.16 times as that of the eastern areas, but it is obviously impossible. Thus, it is impossible to stop the trend of increasing absolute differentials between the eastern and western areas in a quite long period of time.

\footnotetext{
5 Relative differential means the gap in the proportion of aggregate GDP for the eastern and western areas respectively accounting for the whole nation.
} 
Table 5

Comparison of GDP Between Eastern and Western Areas (Unit: billions, \%)

\begin{tabular}{|c|c|c|c|c|c|c|c|}
\hline \multirow[b]{2}{*}{ Year } & \multirow{2}{*}{$\begin{array}{l}\text { National } \\
\text { GDP }\end{array}$} & \multicolumn{4}{|c|}{ GDP in China's western regions } & \multicolumn{2}{|c|}{ GDP in eastern areas } \\
\hline & & Total & $\begin{array}{l}\text { Proportion of } \\
\text { China }(\%)\end{array}$ & $\begin{array}{l}\text { Difference between } \\
\text { state and western area }\end{array}$ & $\begin{array}{l}\text { Difference between } \\
\text { the west and the east }\end{array}$ & Total & $\begin{array}{l}\text { Proportion of } \\
\text { China }(\%)\end{array}$ \\
\hline 2000 & $9,921.46$ & $1,707.07$ & 17.21 & $8,214.39$ & $3,981.44$ & $5,688.51$ & 57.34 \\
\hline 2001 & $10,744.97$ & $1,860.41$ & 17.31 & $8,884.56$ & $4,402.76$ & $6,263.17$ & 58.28 \\
\hline 2002 & $11,720.83$ & $2,052.14$ & 17.51 & $9,668.69$ & $4,932.05$ & $6,984.19$ & 59.59 \\
\hline 2003 & $12,895.89$ & $2,287.92$ & 17.74 & $10,607.97$ & $5,619.94$ & $7,907.86$ & 61.32 \\
\hline 2004 & $14,196.45$ & $2,582.79$ & 18.19 & $11,613.66$ & $6,454.89$ & $9,037.68$ & 63.67 \\
\hline 2005 & $15,800.65$ & $2,924.98$ & 18.51 & $12,875.67$ & $7,339.26$ & $10,264.24$ & 64.97 \\
\hline 2006 & $17,807.33$ & $3,320.69$ & 18.65 & $14,486.65$ & $8,407.62$ & $11,728.31$ & 65.86 \\
\hline 2007 & $20,335.97$ & $3,813.03$ & 18.75 & $16,522.67$ & $9,632.73$ & $13,446.04$ & 66.11 \\
\hline 2008 & $22,288.22$ & $4,307.46$ & 19.33 & $17,980.76$ & $10,671.58$ & $14,979.04$ & 67.20 \\
\hline 2009 & $24,338.74$ & $4,886.79$ & 20.08 & $19,451.95$ & $11,740.65$ & $16,627.44$ & 68.31 \\
\hline 2010 & $26,869.97$ & $5,579.93$ & 20.77 & $21,290.04$ & $13,126.97$ & $18,076.9$ & 69.62 \\
\hline
\end{tabular}

Note. Source: China Statistical Yearbook 2011.

\section{Economic Structural Analysis}

In the absolute GDP differentials between eastern and western areas, the gap of the manufacturing industry in western areas is the largest in 2010. The list in order of the GDP difference between eastern and western areas is: the second industry (7,084.93 billion yuan), the service industry $(5,270.34$ billion yuan), and the agricultural industry (327.56 billion yuan). If the second industry is divided into manufacturing industry and construction industry, the list is: the manufacturing industry (6,395.34 billion yuan), the service industry, the construction industry (690.23 billion yuan), and the agricultural industry (see Table 6 and Figure 2). Therefore, the absolute difference in manufacturing industry between the eastern and western areas is the biggest one.

Table 6

Comparison of the Industries Between Eastern and Western Areas (2010) (Unit: billion, \%)

\begin{tabular}{lcrrrrr}
\hline Areas & \multicolumn{1}{c}{ GDP } & $\begin{array}{l}\text { Agricultural } \\
\text { industry }\end{array}$ & $\begin{array}{l}\text { Second } \\
\text { industry }\end{array}$ & $\begin{array}{l}\text { Manufacturing } \\
\text { industry }\end{array}$ & $\begin{array}{l}\text { Construction } \\
\text { industry }\end{array}$ & Service industry \\
\hline (1) nation & $26,869.97$ & $2,260.11$ & $13,485.58$ & $11,671.72$ & $1,813.86$ & $11,192.84$ \\
(2) west & $5,579.93$ & 603.78 & $2,809.11$ & $2,174.59$ & 634.52 & $2,109.68$ \\
(3) east & $18,076.9$ & 931.34 & $9,894.04$ & $8,569.29$ & $1,324.75$ & $7,380.02$ \\
(2)/(1) $(\%)$ & 20.76 & 26.71 & 20.83 & 18.63 & 34.98 & 18.85 \\
(3)/(1) $(\%)$ & 67.27 & 41.21 & 73.36 & 73.42 & 73.04 & 65.94 \\
(2)/(3) $(\%)$ & 30.86 & 64.83 & 28.39 & 25.38 & 47.90 & 28.59 \\
(1)-(2) & $21,290.04$ & $1,656.33$ & $10,676.47$ & $9,697.13$ & $1,179.34$ & $9,083.16$ \\
(3)-(2) & $12,496.974$ & 327.56 & $7,084.93$ & $6,395.34$ & 690.23 & $5,270.34$ \\
\hline
\end{tabular}

It should be noticed that the differential in service industry is to great extent caused by the gap in manufacturing industry, for instance, the differential in financial business, transportation, post and warehousing in the service industry comes largely from the differential in manufacturing industry because the manufacturing industry in the eastern areas is much more developed so that the demand for the direct service of these service industries is much greater and consequently the volume of business generated by these industries is much bigger than that in the western areas. In addition, the much more developed manufacturing industry in the eastern areas raises the wage level and increases the purchasing power and consuming capability so as to 
promote more rapid development of the service industry such as restaurant and accommodation business, real estate, wholesaling and retailing and so on.

Therefore, accelerating the development of manufacturing industry in the western areas is of the most importance to narrow the gap between the eastern and western areas.

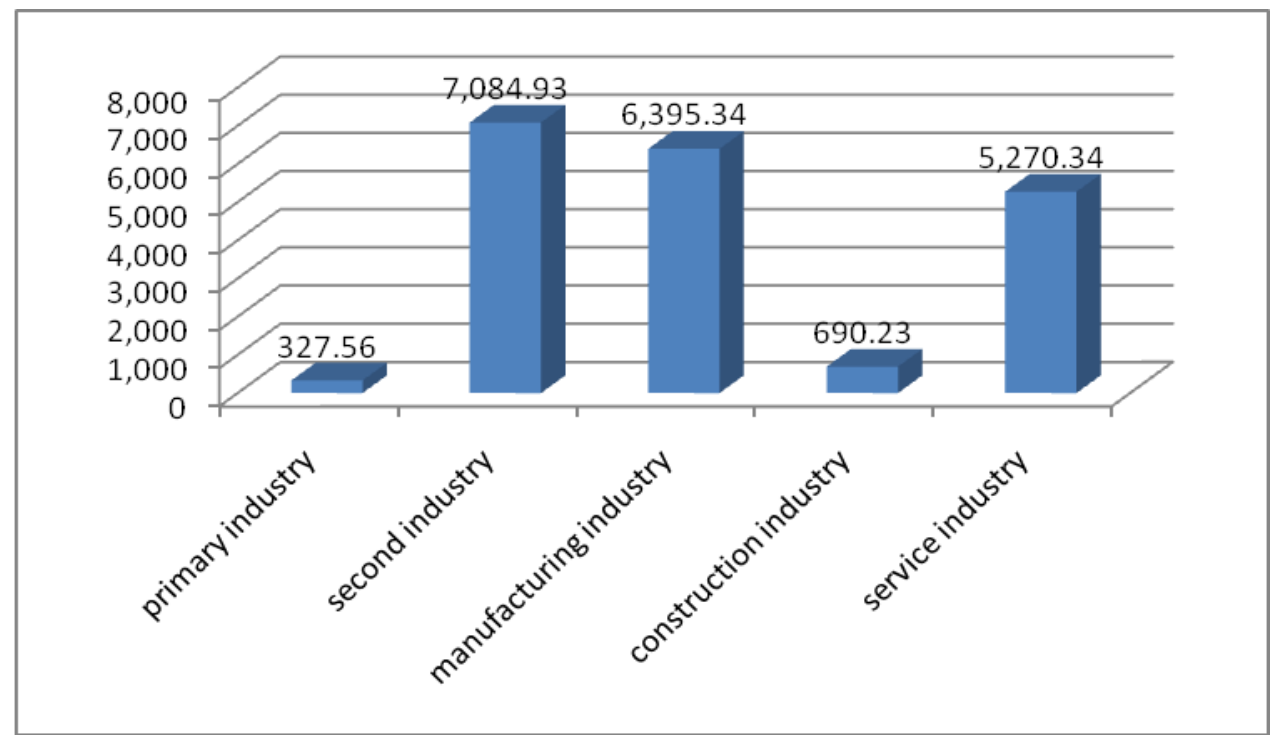

Figure 2. The difference of industries of thing ministry in 2010 (billion).

\section{Conclusions}

The appearance of a Kuznets regional inverted-U Curve in the trend of the absolute differential between eastern and western areas is the great achievement of GCWD policy, but it is in the first half of the inverted U-shaped curve in our choice of time span (1978-2010), and the absolute differential is increasing though the growth rates in the western areas have been a little higher than that in the eastern areas since 2006. Therefore, the Kuznets inverted-U curve is not stable. Seen from economic structure, the differential in second industry, especially the manufacturing industry is the biggest and in industrial correlation degree, the backward of manufacturing industry in the western areas is an important cause for the backward or inequality of service industry. Thus, the strategy for the economic development of the western areas lies in the acceleration of industrialization, through accelerating the development of manufacturing industry to promote the development of service industry and agricultural industry so as to drive the economic development of the western areas as a whole. In the development of manufacturing industry, the western areas must take the new-type industrialization road, transform the mode of industrial development, accelerate technological progress, and upgrade industrial structure, give full play of the advantage of natural resource (especially renewable energy resources such as hydropower and wind power), pay more attention to the sustainable development and vigorously develop low-carbon economy. Meanwhile, the government should give the western areas more policy support in promoting the manufacturing industrial development in the western areas in addition to the support of the construction of infrastructure, especially cultivate and support the development of the characteristic and advantageous industries in the western areas, strengthen the ability of self-development of the western areas, and thus strive to narrow the gap between the eastern and western areas and promote the regional coordinate and sustainable development. 


\section{References}

Cai, F., \& Du, Y. (2001). Regional gap, convergence and western development. Journal of China's Industrial Economy, 2, 48-54.

Guo, J. L., \& Wang, H. W. (2003). A research on Chinese regional capital flow and regional economic disparities. Journal of Management World, 7, 45-58.

Johasen, S. (1991). Estimation and hypothesis of cointegration vectors in Gaussian vector auto-regression modle. Econometric, 59, 1551-1580.

Li, H. N., \& Ye, M. Q. (2006). China's east, middle and west regional economic development gap analysis. Journal of Economic Issues, 2, 4-11.

Liu, S. C., Li, Q., \& Xue, T. D. (1985). Economic development research in China. China: China Statistics Press.

Wang, X. L., \& Fan, G. (2004). An analysis on the regional disparity in China and influencing factors. Journal of Economic Research, 1, 33-44.

Williamson, J. G. (1965). Regional inequality and the process of national development: A description of the patterns. Economic Development and Cultural Change, 13(1), 3-45.

Yang, K. Z. (1994). The study on the changes of regional economic disparities in China. Journal of Economic Research, 94(12), 28-33.

Yang, W. J. (2005). Technical efficiency, technical progress, capital deepening and economic growth: An empirical analysis based on DEA. Journal of The World Economy, 6, 73-96.

Yang, W. M. (1992). The empirical research on income mobility among different regions. Journal of Economic Research, 1, 70-74.

Zhou, Y. C., \& Lu, Y. Q. (2005). An analysis on the industrial structural benefit in the Yangtze River Delta and Pearl River Delta. Journal of Modern Economic Research, 11, 11-14. 
Appendix A

Table A1

The Real per Capita GDP of Western Areas (1978 = 100) (Unit: Yuan)

\begin{tabular}{|c|c|c|c|c|c|c|c|c|c|c|c|c|}
\hline Year & Chongqing & Sichuan & Guizhou & Yunnan & Xizang & Shanxi & Gansu & Qinghai & Ningxia & Xijiang & $\begin{array}{l}\text { Inner } \\
\text { Mongolia }\end{array}$ & Guangxi \\
\hline 1978 & 272.05 & 261.05 & 173.57 & $2,223.32$ & 371.51 & 291.72 & 346.15 & 425.75 & 365.60 & 316.87 & 318.38 & 222.96 \\
\hline 1979 & 292.72 & 280.89 & 186.76 & 240.29 & 399.74 & 313.89 & 372.46 & 458.11 & 393.39 & 340.95 & 342.57 & 239.90 \\
\hline 1980 & 312.11 & 299.31 & 194.74 & 252.44 & 416.97 & 332.18 & 391.48 & 478.15 & 403.51 & 353.24 & 358.69 & 248.69 \\
\hline 1981 & 326.00 & 312.39 & 201.35 & 261.59 & 436.54 & 345.50 & 407.19 & 496.71 & 414.03 & 366.11 & 372.40 & 256.33 \\
\hline 1982 & 352.65 & 336.58 & 215.83 & 279.94 & 468.31 & 371.57 & 436.23 & 526.30 & 440.24 & 395.15 & 397.79 & 274.04 \\
\hline 1983 & 388.10 & 371.39 & 237.20 & 305.97 & 508.57 & 408.25 & 477.71 & 583.64 & 480.84 & 432.61 & 434.86 & 299.91 \\
\hline 1984 & 443.63 & 426.18 & 270.31 & 348.12 & 573.86 & 464.66 & 543.14 & 657.16 & 543.17 & 494.19 & 495.07 & 338.79 \\
\hline 1985 & 499.63 & 479.98 & 302.59 & 389.69 & 644.62 & 520.93 & 608.20 & 736.53 & 604.82 & 553.75 & 555.35 & 377.78 \\
\hline 1986 & 536.29 & 516.09 & 323.54 & 416.68 & 691.34 & 559.65 & 651.96 & 775.15 & 643.37 & 592.83 & 597.18 & 403.66 \\
\hline 1987 & 590.46 & 568.15 & 355.45 & 457.79 & 749.08 & 615.11 & 716.74 & 850.71 & 699.95 & 651.07 & 658.22 & 442.52 \\
\hline 1988 & 650.54 & 623.71 & 388.67 & 500.87 & 817.76 & 673.09 & 785.62 & 933.47 & 762.40 & 714.27 & 722.59 & 483.71 \\
\hline 1989 & 671.46 & 641.85 & 398.87 & 513.52 & 835.25 & 687.75 & 803.72 & 958.18 & 775.47 & 729.00 & 742.05 & 495.86 \\
\hline 1990 & 691.50 & 658.91 & 401.86 & 521.35 & 843.83 & 688.70 & 808.62 & 977.15 & 786.40 & 719.82 & 755.89 & 503.70 \\
\hline 1991 & 750.43 & 714.49 & 432.59 & 561.60 & 905.11 & 741.51 & 871.38 & $1,052.89$ & 833.08 & 772.86 & 817.45 & 539.58 \\
\hline 1992 & 853.85 & 811.69 & 487.42 & 633.20 & $1,024.92$ & 836.65 & 982.98 & $1,184.55$ & 938.03 & 868.39 & 924.12 & 608.53 \\
\hline 1993 & 968.28 & 919.67 & 547.57 & 711.65 & $1,147.70$ & 942.79 & $1,105.24$ & $1,332.38$ & $1,051.56$ & 974.68 & $1,041.18$ & 684.32 \\
\hline 1994 & $1,087.42$ & $1,032.16$ & 610.46 & 793.75 & $1,275.90$ & $1,054.54$ & $1,232.54$ & $1,484.50$ & $1,167.94$ & $1,084.00$ & $1,162.85$ & 764.41 \\
\hline 1995 & $1,199.79$ & $1,136.23$ & 667.54 & 869.27 & $1,391.79$ & $1,158.84$ & $1,333.63$ & $1,622.82$ & $1,272.89$ & $1,181.51$ & $1,276.42$ & 838.64 \\
\hline 1996 & $1,310.77$ & $1,241.76$ & 724.68 & 944.01 & $1,506.06$ & $1,264.45$ & $1,449.93$ & $1,759.71$ & $1,378.85$ & $1,278.28$ & $1,390.24$ & 913.37 \\
\hline 1997 & $1,423.01$ & $1,322.49$ & 780.75 & $1,018.55$ & $1,619.33$ & $1,371.38$ & $1,567.38$ & $1,892.06$ & $1,481.26$ & $1,373.36$ & $1,506.89$ & 988.69 \\
\hline 1998 & $1,526.01$ & $1,415.50$ & 829.93 & $1,085.07$ & $1,718.44$ & $1,468.10$ & $1,673.37$ & $2,011.86$ & $1,573.53$ & $1,456.35$ & $1,611.76$ & $1,056.55$ \\
\hline 1999 & $1,635.71$ & $1,513.37$ & 880.75 & $1,154.51$ & $1,820.70$ & $1,570.54$ & $1,784.08$ & $2,135.68$ & $1,678.03$ & $1,543.64$ & $1,722.28$ & $1,128.01$ \\
\hline 2000 & $1,762.64$ & $1,630.84$ & 943.20 & $1,237.23$ & $1,958.66$ & $1,690.59$ & $1,923.67$ & $2,284.11$ & $1,783.16$ & $1,605.69$ & $1,859.38$ & $1,213.44$ \\
\hline 2001 & $1,904.80$ & $1,758.50$ & $1,009.96$ & $1,325.59$ & $2,080.97$ & $1,823.47$ & $2,068.85$ & $2,445.40$ & $1,900.36$ & $1,714.00$ & $2,009.55$ & $1,303.77$ \\
\hline 2002 & $2,067.30$ & $1,911.02$ & $1,090.84$ & $1,430.72$ & $2,236.09$ & $1,981.07$ & $2,241.21$ & $2,637.39$ & $2,040.46$ & $1,841.32$ & $2,190.35$ & $1,412.24$ \\
\hline 2003 & $2,262.72$ & $2,096.07$ & $1,189.96$ & $1,558.67$ & $2,432.92$ & $2,170.22$ & $2,456.41$ & $2,874.61$ & $2,214.03$ & $1,995.52$ & $2,408.90$ & $1,542.61$ \\
\hline 2004 & $2,479.67$ & $2,300.80$ & $1,298.53$ & $1,700.68$ & $2,639.13$ & $2,379.37$ & $2,687.57$ & $3,135.10$ & $2,404.12$ & $2,164.28$ & $2,647.35$ & $1,687.04$ \\
\hline 2005 & $2,738.44$ & $2,721.04$ & $1,512.84$ & $1,878.16$ & $2,905.83$ & $2,637.83$ & $3,020.40$ & $3,464.02$ & $2,640.13$ & $2,352.75$ & $2,944.33$ & $1,970.15$ \\
\hline 2006 & $3,056.84$ & $3,082.03$ & $1,692.32$ & $2,100.61$ & $3,227.50$ & $2,960.20$ & $3,387.52$ & $3,867.42$ & $2,935.33$ & $2,599.20$ & $3,302.25$ & $2,192.08$ \\
\hline 2007 & $3,450.57$ & $3,536.83$ & $1,929.49$ & $2,381.72$ & $3,645.79$ & $3,367.82$ & $3,851.15$ & $4,383.29$ & $3,318.20$ & $2,903.68$ & $3,757.52$ & $2,476.90$ \\
\hline 2008 & $3,757.75$ & $3,872.32$ & $2,098.08$ & $2,594.51$ & $3,955.24$ & $3,678.54$ & $4,204.49$ & $4,788.23$ & $3,590.78$ & $3,129.63$ & $4,104.15$ & $2,688.46$ \\
\hline 2009 & $4,076.84$ & $4,200.81$ & $2,286.20$ & $2,813.51$ & $4,270.91$ & $4,002.99$ & $4,575.32$ & $5,196.28$ & $3,874.00$ & $3,370.44$ & $4,463.23$ & $2,909.20$ \\
\hline 2010 & $5,116.92$ & $4,724.59$ & $2,759.01$ & $3,089.24$ & $4,548.73$ & $4,468.94$ & $5,205.96$ & $5,683.00$ & $4,228.39$ & $3,681.52$ & $4,834.09$ & $3,387.58$ \\
\hline
\end{tabular}


Table A2

The Real per Capita GDP of Eastern Areas $(1978=100)$ (Unit: Yuan)

\begin{tabular}{|c|c|c|c|c|c|c|c|c|c|c|}
\hline Year & Beijing & Tianjin & Hebei & Liaoning & Shanghai & Jiangsu & Zhejiang & Fujian & Shandong & Guangdong \\
\hline 1978 & $1,248.17$ & $1,141.15$ & 361.99 & 675.31 & $2,496.43$ & 427.22 & 329.84 & 270.59 & 314.87 & 366.99 \\
\hline 1979 & $1,305.57$ & $1,196.07$ & 383.68 & 712.37 & $2,578.39$ & 452.55 & 349.07 & 285.46 & 333.56 & 386.85 \\
\hline 1980 & $1,396.62$ & $1,280.18$ & 410.89 & 762.49 & $2,760.18$ & 486.90 & 375.05 & 305.78 & 358.45 & 412.39 \\
\hline 1981 & $1,446.07$ & $1,327.28$ & 425.26 & 791.71 & $2,864.55$ & 506.36 & 390.19 & 316.94 & 372.24 & 426.27 \\
\hline 1982 & $1,547.71$ & $1,419.59$ & 454.92 & 849.27 & $3,075.88$ & 544.82 & 419.62 & 339.24 & 400.42 & 456.79 \\
\hline 1983 & $1,683.94$ & $1,553.48$ & 498.52 & 932.18 & $3,372.40$ & 599.64 & 460.78 & 371.10 & 439.93 & 499.29 \\
\hline 1984 & $1,913.42$ & $1,766.20$ & 567.16 & $1,066.11$ & $3,849.48$ & 686.61 & 526.72 & 421.50 & 501.85 & 566.63 \\
\hline 1985 & $2,122.88$ & $1,981.01$ & 636.49 & $1,199.41$ & $4,325.26$ & 773.84 & 592.26 & 471.89 & 565.16 & 633.89 \\
\hline 1986 & $2,214.77$ & $2,129.71$ & 683.18 & $1,291.79$ & $4,648.93$ & 834.78 & 638.25 & 506.95 & 608.85 & 679.85 \\
\hline 1987 & $2,389.99$ & $2,336.70$ & 751.16 & $1,421.65$ & $5,115.56$ & 919.93 & 703.38 & 555.27 & 669.58 & 746.63 \\
\hline 1988 & $2,624.85$ & $2,567.52$ & 823.53 & $1,561.95$ & $5,633.75$ & $1,009.27$ & 773.50 & 608.12 & 733.86 & 817.28 \\
\hline 1989 & $2,719.00$ & $2,630.72$ & 844.49 & $1,604.28$ & $5,798.37$ & $1,034.56$ & 797.49 & 623.26 & 747.64 & 836.87 \\
\hline 1990 & $2,777.20$ & $2,687.74$ & 837.28 & $1,648.22$ & $5,988.28$ & $1,037.55$ & 822.97 & 623.25 & 747.78 & 838.16 \\
\hline 1991 & $3,060.25$ & $2,796.83$ & 905.29 & $1,766.97$ & $6,262.42$ & $1,120.20$ & 905.67 & 663.05 & 809.20 & 887.83 \\
\hline 1992 & $3,470.63$ & $3,156.87$ & $1,025.14$ & $2,005.50$ & $7,127.54$ & $1,267.30$ & $1,026.33$ & 748.47 & 920.13 & $1,000.88$ \\
\hline 1993 & $3,919.02$ & $3,566.06$ & $1,157.20$ & $2,270.45$ & $8,097.34$ & $1,432.41$ & $1,161.22$ & 843.64 & $1,044.55$ & $1,126.30$ \\
\hline 1994 & $4,380.69$ & $4,002.56$ & $1,297.58$ & $2,551.80$ & $9,109.76$ & $1,607.41$ & $1,304.62$ & 944.15 & $1,177.30$ & $1,258.08$ \\
\hline 1995 & $4,370.13$ & $4,407.12$ & $1,428.48$ & $2,813.47$ & $9,684.28$ & $1,771.77$ & $1,438.87$ & $1,029.89$ & $1,300.90$ & $1,359.24$ \\
\hline 1996 & $4,777.20$ & $4,817.76$ & $1,560.13$ & $3,077.16$ & $10,624.02$ & $1,937.13$ & $1,574.20$ & $1,124.69$ & $1,425.77$ & $1,475.37$ \\
\hline 1997 & $5,300.68$ & $5,237.39$ & $1,694.25$ & $3,344.95$ & $11,307.48$ & $2,105.71$ & $1,684.66$ & $1,221.23$ & $1,549.79$ & $1,591.76$ \\
\hline 1998 & $5,688.33$ & $5,624.00$ & $1,814.72$ & $3,590.45$ & $12,134.83$ & $2,259.89$ & $1,808.04$ & $1,310.10$ & $1,661.16$ & $1,694.32$ \\
\hline 1999 & $6,068.89$ & $6,040.60$ & $1,939.93$ & $3,851.51$ & $12,972.35$ & $2,421.91$ & $1,937.77$ & $1,402.86$ & $1,778.88$ & $1,791.78$ \\
\hline 2000 & $6,094.88$ & $6,274.30$ & $2,084.32$ & $4,162.74$ & $12,633.05$ & $2,584.93$ & $2,045.58$ & $1,479.02$ & $1,903.97$ & $1,832.46$ \\
\hline 2001 & $6,476.89$ & $6,775.00$ & $2,248.97$ & $4,497.65$ & $13,910.94$ & $2,788.91$ & $2,207.28$ & $1,587.86$ & $2,052.27$ & $1,965.24$ \\
\hline 2002 & $6,866.94$ & $7,368.74$ & $2,440.26$ & $4,895.93$ & $15,072.54$ & $3,031.67$ & $2,390.27$ & $1,719.19$ & $2,228.68$ & $2,123.12$ \\
\hline 2003 & 7,384.08 & $8,075.34$ & $2,671.40$ & $5,377.76$ & $15,749.95$ & $3,324.32$ & $2,611.34$ & $1,879.60$ & $2,440.54$ & $2,308.05$ \\
\hline 2004 & $7,927.17$ & $8,776.72$ & $2,923.48$ & $5,910.18$ & $17,029.48$ & $3,646.22$ & $2,850.28$ & $2,055.56$ & $2,670.53$ & $2,433.69$ \\
\hline 2005 & $8,565.66$ & $9,591.52$ & $3,234.21$ & $6,572.46$ & $18,571.95$ & $4,035.85$ & $3,057.39$ & $2,272.54$ & $2,950.74$ & $2,446.74$ \\
\hline 2006 & $9,388.74$ & $10,485.40$ & $3,619.27$ & $7,318.73$ & $20,499.08$ & $4,502.17$ & $3,388.14$ & $2,544.00$ & $3,302.92$ & $2,724.23$ \\
\hline 2007 & $10,377.46$ & $11,541.35$ & $4,105.21$ & $8,303.03$ & $22,861.42$ & $5,089.40$ & $3,806.96$ & $2,885.73$ & $3,747.47$ & $3,062.43$ \\
\hline 2008 & $10,961.06$ & $11,996.90$ & $4,471.08$ & $9,067.08$ & $24,665.61$ & $5,541.91$ & $4,124.81$ & $3,143.55$ & $4,086.69$ & $3,324.04$ \\
\hline 2009 & $11,550.68$ & $12,535.47$ & $4,847.16$ & $9,883.89$ & $26,450.21$ & $6,009.18$ & $4,448.43$ & $3,408.16$ & $4,434.01$ & $3,591.47$ \\
\hline 2010 & $11,421.54$ & $13,099.93$ & $5,239.12$ & $10,786.28$ & $24,389.43$ & $6,521.29$ & $4,676.47$ & $3,700.22$ & $4,841.25$ & $3,664.85$ \\
\hline
\end{tabular}

